\title{
Loss of Parp-I affects gene expression profile in a genome-wide manner in ES cells and liver cells
} Hideki Ogino ${ }^{1,2}$, Tadashige Nozaki², Akemi Gunji², Miho Maeda1,3, Hiroshi Suzuki ${ }^{4}$, Tsutomu Ohta ${ }^{5}$, Yasufumi Murakami ${ }^{3}$, Hitoshi Nakagama², Takashi Sugimura $^{2}$ and Mitsuko Masutani*1,2

Address: ${ }^{A}$ ADP-ribosylation in Oncology Project, National Cancer Center Research Institute, 1-1, Tsukiji 5-chome, Chuo-ku, Tokyo 104-0045, Japan, ${ }^{2}$ Biochemistry Division, National Cancer Center Research Institute, 1-1, Tsukiji 5-chome, Chuo-ku, Tokyo 104-0045, Japan, ${ }^{3}$ Department of Biological Science \& Technology, Faculty of Industrial Science \& Technology, Tokyo University of Science, 2641, Yamazaki, Noda, Chiba 2788510, Japan, ${ }^{4}$ Chugai Pharmaceutical Co. Ltd., 1-135, Komakado, Gotemba, Shizuoka 412-0038, Japan and ${ }^{5}$ Center for Medical Genomics, National Cancer Center Research Institute, 1-1, Tsukiji, 5-chome, Chuo-ku, Tokyo 104-0045, Japan

Email: Hideki Ogino - hogino@gan2.res.ncc.go.jp; Tadashige Nozaki - nozaki@cc.osaka-dent.ac.jp; Akemi Gunji - agunji@ntmc.hosp.go.jp; Miho Maeda - mihmaeda@gan2.res.ncc.go.jp; Hiroshi Suzuki - hisuzuki@obihiro.ac.jp; Tsutomu Ohta - cota@gan2.res.ncc.go.jp;

Yasufumi Murakami - yasufumi@rs.noda.tus.ac.jp; Hitoshi Nakagama - hnakagam@gan2.res.ncc.go.jp;

Takashi Sugimura - tsugimur@gan2.res.ncc.go.jp; Mitsuko Masutani* - mmasutan@gan2.res.ncc.go.jp

* Corresponding author

Published: 10 July 2007

BMC Genomics 2007, 8:227 doi:10.1/86/|47|-2/64-8-227
Received: 20 March 2007

Accepted: 10 July 2007

This article is available from: http://www.biomedcentral.com//47I-2/64/8/227

(c) 2007 Ogino et al; licensee BioMed Central Ltd.

This is an Open Access article distributed under the terms of the Creative Commons Attribution License (http://creativecommons.org/licenses/by/2.0), which permits unrestricted use, distribution, and reproduction in any medium, provided the original work is properly cited.

\section{Background}

Following the publication of the paper 'Loss of Parp-1 affects gene expression profile in a genome-wide manner in ES cells and liver cells' [1], we found an error in our data.

In the article, we used six replicates of microarray data of wild-type ES cells for comparison with the microarray data of Parp-1 knockout ES cells. We found that three replicate data were carelessly included in the data for wildtype ES cells. The comparison should have been carried out between three replicates for the Parp-1+/+ ES cell line, J1, and three replicates for two Parp-1\%- ES cell lines, 21058 and 226-47, respectively.

Therefore, we re-analyzed the data in ES cells according to the same criteria. The consequences of this error are reflected in changes to our results although the conclusions we obtained in the study are not affected.

\section{Corrected sentences in the Abstract}

Here, we demonstrate that of the 9,640 genes analyzed, in Parp-1\% ES cells. 3.6\% showed altered gene expression. Of these, $2.5 \%$ and $1.1 \%$ of the genes were down- or up-reg-
Table I: Differential expression of genes between Parp- $I^{+/+}$and

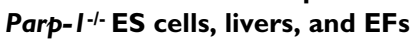

\begin{tabular}{|c|c|c|c|c|c|}
\hline \multirow[b]{3}{*}{$p$-value cut offa } & \multicolumn{5}{|c|}{ No. of genes } \\
\hline & \multirow[b]{2}{*}{ Total } & \multicolumn{2}{|c|}{ Parp- $\left.\right|^{-/-}<$Parp- $I^{+/+}$} & \multicolumn{2}{|c|}{ Parp-I-I- > Parp- $I^{+/+}$} \\
\hline & & Total & $\begin{array}{l}\text { 2-fold or } \\
\text { greater }\end{array}$ & Total & $\begin{array}{l}2 \text {-fold or } \\
\text { greater }\end{array}$ \\
\hline \multicolumn{6}{|l|}{ ES cells ${ }^{c}$} \\
\hline Totalb & 9,640 & 5,065 & 1,056 & 4,481 & 1,520 \\
\hline$p<0.05^{b}$ & 893 & 663 & 238 & 230 & 106 \\
\hline \multicolumn{6}{|l|}{ Livers $^{d}$} \\
\hline Totalb & 12,353 & 7,138 & 1,184 & 4,860 & $\mathrm{I}, 038$ \\
\hline$p<0.05^{b}$ & 1,616 & 1,190 & 253 & 426 & 158 \\
\hline$p<0.0 I^{b}$ & 641 & 515 & 100 & 126 & 43 \\
\hline \multicolumn{6}{|l|}{$\mathrm{EFs}^{\mathrm{e}}$} \\
\hline Total & 12,357 & 5,042 & 707 & 7,317 & 501 \\
\hline$p<0.05$ & 996 & 390 & 216 & 606 & 205 \\
\hline \multicolumn{6}{|c|}{$\begin{array}{l}\text { aAnalyzed by One-Way ANOVA (non-parametric test known as the Mann- } \\
\text { Whitney U test) } \\
\text { bThese genes were presented in Fig. I. } \\
\text { cParp- } I^{+++} \text {ES cell clone, JI, and Parp- } I^{---} \text {ES cell clones, } 210-58 \text { and } 226-47 \text {, were } \\
\text { used. } \\
\text { dTwo mice were used for each genotype. } \\
\text { eThree EFs obtained from three embryos were analyzed as triplicate experiment }\end{array}$} \\
\hline
\end{tabular}



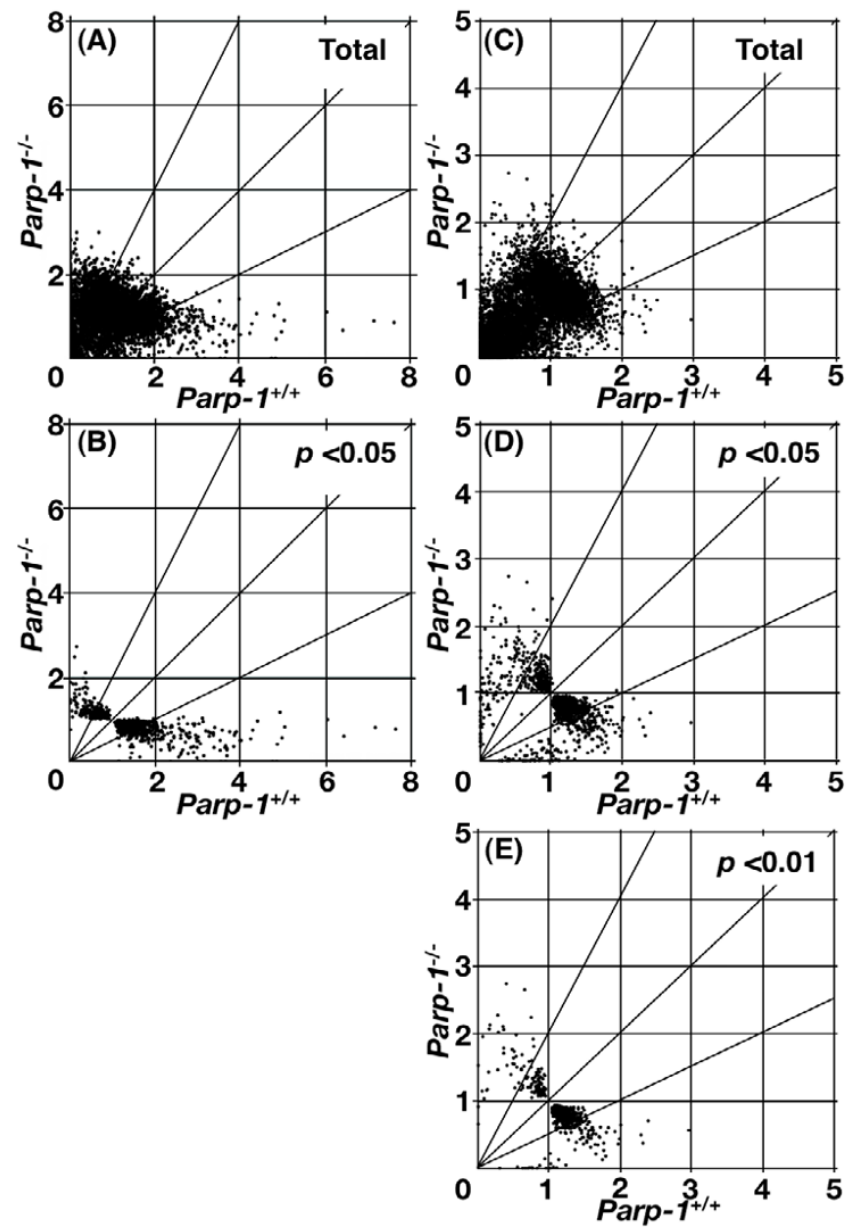

Figure I

Effect of Parp-I deficiency on gene expression. Gene expression data from microarray analyses are plotted for Parp- $I^{-/}$versus wild-type (Parp- $I^{+/+}$) ES cell lines (A) \& (B). Horizontal and vertical axes represent expression levels normalized for an individual gene. Each point represents normalized expression data for an individual gene. The genes that showed standard deviation greater than 2.0 in the normalized data of both genotypes $(A)$ were excluded and gene lists were constructed with $p<0.05$ (B). Fig. ID-F in the original article [I] remains unchanged and is presented as $(\mathrm{C})-(\mathrm{E})$, respectively.

ulated by 2 -fold or greater, respectively, compared with Parp-1+/+ ES cells $(p<0.05)$.

\section{Corrected results in the text}

\section{Gene expression profile in Parp-I-/- ES cells}

A comparison of the basal gene expression profiles in Parp-1\%EScells to their wild-type (Parp-1+/+) counterparts, is presented in Fig. $1 \mathrm{~A} \& 1 \mathrm{~B}$ (corrected) and Table 1 (corrected). We found the expression of $(344 / 9,640)$ genes, namely $3.6 \%$, was different by at least 2 -fold between
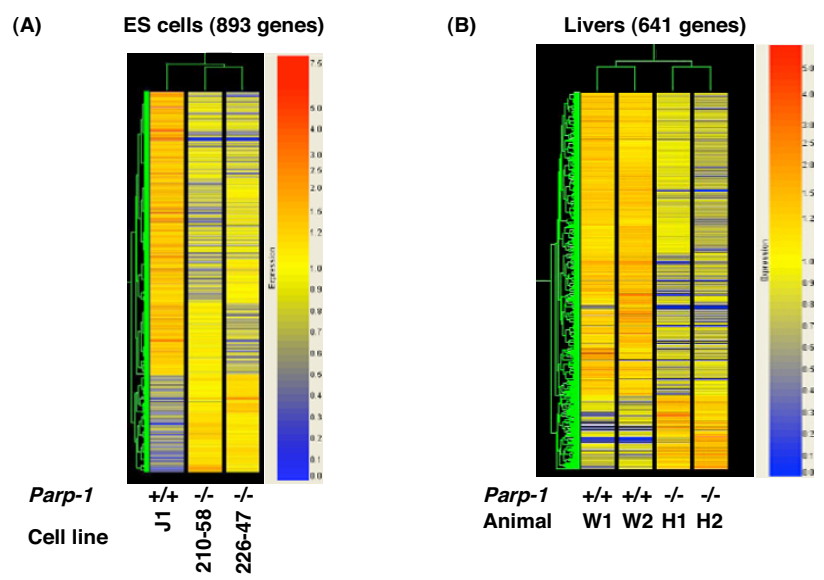

(C) $p<0.05$, Parp-1-1- $<$ Parp-1+/+

(D) $p<0.05$, Parp $-1^{-/ /}>$Parp $-1^{+/+}$
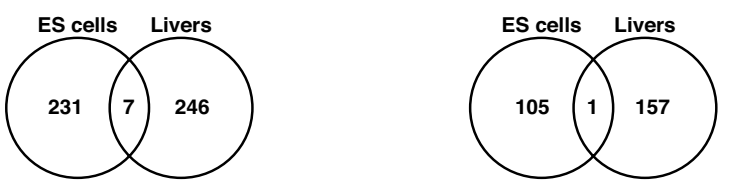

Figure 2

Comparison of gene expression profiles among cell lines or cell types. Heatmaps of gene expression profiles in ES cells (A). We constructed the heatmaps using the gene lists containing the genes that showed a difference at $p<0.05$ in ES cells. Each heatmap is constructed using GeneSpring GX ver. 7.3.I. Numbers of genes down-(C) or up-(D) regulated in common between Parp-/-/ES cells and livers. The numbers of the genes are indicated in Venn diagrams. These genes showed the difference with at least 2-fold between Parp- $I^{+/+}$and Parp- $I^{-I^{-}}(p<0.05)$. Fig. $2 \mathrm{~B}$ in the original article [I] remains unchanged and is presented as $(B)$. Fig. 2D \& $F$ in the original article [I] are removed and Fig. 2C \& $E$ were corrected in the original article [I] and are presented as (C) and (D).

Parp-1/-and Parp-1+/+ES cells ( $p<0.05$ ) (Fig. 1B (corrected) and Table 1 (corrected)). Notably, a larger fraction of the genes, being $2.5 \%(238 / 9,640)$, was down-regulated, whereas only $1.1 \%(106 / 9,640)$ of the genes were up-regulated (see Table 1 (corrected)).

We also made the heatmaps using the gene lists containing the 893 genes that showed a difference at $p<0.05$ in ES cells (Fig. 2A (corrected)). Although we used independently isolated Parp-1\% ES cell clones, a clear and common alteration in the gene expression profile was observed (see Fig. 2A (corrected), and Tables 2 (corrected) and 3 (corrected)). 


\begin{tabular}{|c|c|c|c|c|c|c|}
\hline \multirow[b]{2}{*}{ Accession No. } & \multicolumn{3}{|c|}{ Fold change ${ }^{a)}$} & \multirow[b]{2}{*}{ Symbol } & \multirow[b]{2}{*}{ Chromosome } & \multirow[b]{2}{*}{ Gene description } \\
\hline & W vs H & JI vs $210-58$ & JI vs $226-47$ & & & \\
\hline \multicolumn{7}{|c|}{ Cell cycle/cell proliferation/cell death } \\
\hline AWI22355 & 3.2 & 5.2 & 2.3 & Prkcbpl & 2 & Protein kinase $\mathrm{C}$ binding protein I \\
\hline AF067395 & 2.9 & 2.9 & 2.9 & Bnip3l & 14 & BCL2/adenovirus EIB 19 kDa-interacting protein \\
\hline Al842277 & 2.7 & 2.3 & 3.2 & $\lg f b p 3$ & 11 & Insulin-like growth factor binding protein 3 \\
\hline U95826 & 2.2 & 2.5 & 1.9 & Ccng2 & 5 & Cyclin G2 \\
\hline \multicolumn{7}{|c|}{ Cell structure/cell adhesion } \\
\hline U1674I & 4.1 & 6.3 & 3.1 & Capza2 & 6 & Capping protein (actin filament) muscle Z-line, alpha 2 \\
\hline All 32380 & 3.6 & 3.1 & 4.3 & Fndc3a & 14 & Fibronectin type III domain containing 3a \\
\hline Al505453 & 2.9 & 2.5 & 3.4 & Myh9 & 15 & Myosin, heavy polypeptide 9 , non-muscle \\
\hline AW208938 & 2.4 & 3.2 & 2.0 & Pkp2 & 16 & Plakophilin 2 \\
\hline M76।24 & 2.4 & 2.2 & 2.6 & Tacstd I & 17 & Tumor-associated calcium signal transducer I \\
\hline \multicolumn{7}{|l|}{ Metabolism } \\
\hline U73820 & 5.5 & 5.2 & 5.8 & GalntI & 18 & Polypeptide GalNAc transferase-TI (ppGaNTase-TI) \\
\hline Al84I 270 & 3.4 & 2.4 & 6.4 & Gstm I & 3 & Glutathione S-transferase, mul \\
\hline AV308550 & 2.6 & 4.1 & 1.9 & Piga & $x$ & Phosphatidylinositol glycan, class A \\
\hline Al851912 & 2.3 & 2.2 & 2.5 & Rps27 & 3 & Ribosomal protein $\$ 27$ \\
\hline Al852/44 & 2.1 & 2.9 & 1.7 & Pbef-pending & 12 & Pre-B-cell colony-enhancing factor \\
\hline U65986 & 2.1 & 1.9 & 2.5 & Anxall & 14 & Annexin All \\
\hline D50264 & 2.1 & 1.4 & 4.1 & Pigf & 17 & Phosphatidylinositol glycan, class F \\
\hline AF03।486 & 2.0 & 2.0 & 2.0 & Sms & $\mathrm{x}$ & Spermidine synthase \\
\hline Al845882 & 2.0 & 2.5 & 1.7 & Acypl & 12 & Acylphosphatasel, erythrocyte (common) type \\
\hline \multicolumn{7}{|c|}{ Protein biosynthesis/degradation } \\
\hline Al852581 & 3.0 & 3.0 & 3.1 & Ide & 19 & Insulin degradating enzyme \\
\hline Al4|405I & 3.0 & 1.8 & 9.1 & Usp24 & 4 & Ubiquitin specific protease 24 \\
\hline$A W 121012$ & 2.9 & 2.8 & 3.0 & Rnfl9 & 15 & Ring finger protein 19 \\
\hline X92665 & 2.9 & 2.5 & 3.4 & Ube2el & 14 & Ubiquitin-conjugating enzyme UbcM3 \\
\hline AW048882 & 2.2 & 2.8 & 1.8 & lars & 13 & Isoleucine-tRNA synthetase \\
\hline AA867340 & 2.2 & 1.9 & 2.6 & Psme4 & 11 & Proteasome (prosome, macropain) activator subunit \\
\hline AB024427 & 2.2 & 2.3 & 2.1 & Rnfll & 4 & Ring finger protein II \\
\hline \multicolumn{7}{|l|}{ Signaling } \\
\hline Al846023 & 4.6 & 2.8 & 13.1 & Arl7 & I & ADP-ribosylation factor-like 7 \\
\hline AA260005 & 2.8 & 2.7 & 2.8 & Pawr & 10 & PPKC, apoptosis, WTI, regulator \\
\hline Al3। 7205 & 2.6 & 2.4 & 2.7 & Map3kl & 13 & Mitogen activated protein kinase kinase kinase I \\
\hline AF035644 & 2.3 & 2.0 & 2.7 & Ptp $4 a 2$ & 4 & Protein tyrosine phosphatase $4 \mathrm{a} 2$ \\
\hline M21019 & 2.3 & 1.9 & 2.9 & Rras & 7 & Harvey rat sarcoma oncogene, subgroup $R$ \\
\hline All94248 & 2.2 & 2.5 & 1.9 & Csnk2al & 2 & Casein kinase II, alpha I polypeptide \\
\hline
\end{tabular}




\begin{tabular}{|c|c|c|c|c|c|c|}
\hline Al854006 & 2.0 & 2.0 & 2.1 & Set & 2 & SET translocation \\
\hline D83921 & 2.0 & 1.9 & 2.1 & Ebaf & 1 & Endometrial bleeding associated factor \\
\hline \multicolumn{7}{|c|}{ Transcription/replication } \\
\hline$X 14206$ & 9.9 & 8.4 & 11.9 & Adprtl & I & Poly(ADP-ribose) polymerase I \\
\hline M99167 & 3.0 & 6.2 & 2.0 & Hnrpal & 15 & Heterogeneous nuclear ribonucleoprotein Al \\
\hline AW 107922 & 2.8 & 3.7 & 2.2 & Soxll & 12 & SRY-box containing gene II \\
\hline Al849135 & 2.5 & 2.5 & 2.5 & Foхо3a & 10 & Forkhead box 03a \\
\hline Y07836 & 2.5 & 2.3 & 2.8 & Bhlhb2 & 6 & Basic-helix-loop-helix domain containing, class B2 \\
\hline X74760 & 2.5 & 2.3 & 2.7 & Notch3 & 17 & Notch gene homolog 3, (Drosophila) \\
\hline Al447783 & 2.1 & 2.4 & 1.9 & Helb & 10 & Helicase (DNA) B \\
\hline X94694 & 2.1 & 2.7 & 1.7 & Tcfap 2c & 2 & Transcription factor AP-2, gamma \\
\hline AF07786I & 2.1 & 2.2 & 2.1 & Id 2 & 12 & Inhibitor of DNA binding 2 \\
\hline Al605405 & 2.0 & 1.9 & 2.3 & Phfl3 & 4 & PHD finger protein 13 \\
\hline D78382 & 2.0 & 1.7 & 2.6 & Tobl & 11 & Transducer of ErbB2.I \\
\hline \multicolumn{7}{|l|}{ Transport } \\
\hline AV356315 & 4.1 & 5.5 & 3.3 & Lmanl & 18 & Lectin, mannose-binding, I \\
\hline AV298789 & 2.9 & 2.6 & 3.2 & Ranbp5 & 14 & Ran binding protein 5 \\
\hline D88315 & 2.2 & 2.2 & 2.2 & Hiatl & 3 & Hippocampus abundant gene transcript I \\
\hline \multicolumn{7}{|l|}{ Unknown } \\
\hline Al845617 & 3.5 & 3.5 & 3.4 & $\begin{array}{l}2610019 A 0 \\
5 R i k\end{array}$ & 11 & Hypothetical protein \\
\hline Al852287 & 3.2 & 3.3 & 3.2 & Ankrd28 & 14 & Ankyrin repeat domain 28 \\
\hline Al83677I & 3.0 & 2.8 & 3.3 & $\begin{array}{l}2900008 \mathrm{M} \\
\text { 13Rik }\end{array}$ & 15 & Unknown EST \\
\hline AA684456 & 2.9 & 2.1 & 4.5 & $\begin{array}{l}2310015 \mathrm{NO} \\
7 R i k\end{array}$ & 7 & Hypothetical protein \\
\hline Al848435 & 2.8 & 1.9 & 4.8 & C78339 & 13 & Unknown EST \\
\hline AW 123157 & 2.8 & 2.5 & 3.1 & $\begin{array}{l}\text { I70005 IEO } \\
\text { 9Rik }\end{array}$ & 11 & Hypothetical protein \\
\hline AWI24843 & 2.6 & 3.1 & 2.3 & C85108 & 4 & Unknown EST \\
\hline AA710439 & 2.6 & 2.0 & 3.6 & $\begin{array}{l}623042 \text { IPO } \\
5 R i k\end{array}$ & 16 & Unknown EST \\
\hline Al853444 & 2.5 & 1.8 & 3.9 & $\begin{array}{l}2610042 L 0 \\
4 R i k\end{array}$ & 14 & Hypothetical protein \\
\hline Al853444 & 2.2 & 2.1 & 2.3 & $\begin{array}{l}2610042 L 0 \\
4 R i k\end{array}$ & 14 & Hypothetical protein \\
\hline AW 121353 & 2.1 & 1.6 & 3.1 & Lrrc8 & 2 & Luecine rich repeat containing 8 \\
\hline Al037493 & 2.1 & 1.5 & 3.4 & $T b c / d / 5$ & 10 & $\mathrm{TBCI}$ domain family, member 15 \\
\hline Al461803 & 2.1 & 2.2 & 1.9 & $\begin{array}{l}\text { I300006CI } \\
\text { 9Rik }\end{array}$ & 9 & Hypothetical protein \\
\hline AW049969 & 2.0 & 2.0 & 2.1 & $\begin{array}{l}\text { C330005LO } \\
\text { 2Rik }\end{array}$ & 9 & Hypothetical protein \\
\hline Al847483 & 2.0 & 2.0 & 2.0 & Tmem4lb & 7 & Transmembrane protein 4IB \\
\hline
\end{tabular}


Table 3: Genes up-regulated in Parp- $\left.\right|^{-/-}$ES cells

\begin{tabular}{|c|c|c|c|c|c|c|}
\hline \multirow[b]{2}{*}{ Accession No. } & \multicolumn{3}{|c|}{ Fold changea) } & \multirow[b]{2}{*}{ Symbol } & \multirow[b]{2}{*}{ Chromosome } & \multirow[b]{2}{*}{ Gene description } \\
\hline & $\mathrm{H}$ vs W & $210-58$ vs J। & $226-47$ vs JI & & & \\
\hline \multicolumn{7}{|c|}{ Cell cycle/cell proliferation/cell death } \\
\hline$\times 58196$ & 3.1 & 3.3 & 2.9 & $H 19$ & 7 & HI9 non-coding RNA \\
\hline Al842665 & 3.0 & 3.1 & 2.8 & Taxlbp3 & 11 & Human T-cell leukemia virus type I binding protein 3 \\
\hline \multicolumn{7}{|c|}{ Cell structure/cell adhesion } \\
\hline$\times 04017$ & 2.3 & 2.3 & 2.3 & Sparc & 11 & Cysteine-rich glycoprotein SPARC \\
\hline M2607I & 2.1 & 2.5 & 1.8 & F3 & 3 & Coagulation factor III \\
\hline M91236 & 2.1 & 2.1 & 2.1 & Gjb5 & 4 & Gap junction membrane channel protein beta 5 \\
\hline \multicolumn{7}{|c|}{ Immune response } \\
\hline UI3705 & 2.3 & 2.1 & 2.4 & Gpx3 & 11 & Glutathione peroxidase 3 \\
\hline \multicolumn{7}{|l|}{ Metabolism } \\
\hline AWI 20625 & 2.3 & 1.9 & 2.7 & Pgd & 4 & Phosphogluconate dehydrogenase \\
\hline M64782 & 2.2 & 1.9 & 2.5 & Folrl & 7 & Folate-binding protein I (FBPI) \\
\hline X97755 & 2.0 & 2.1 & 2.0 & Ebp & $x$ & Phenylalkylamine $\mathrm{Ca}^{2+}$ antagonist (emopamil) binding protein \\
\hline \multicolumn{7}{|c|}{ Protein biosynthesis/degradation } \\
\hline W7I352 & 3.9 & 4.2 & 3.6 & Bag2 & I & Bcl2-associated athanogene 2 \\
\hline Al844I75 & 3.4 & 3.4 & 3.4 & Mrps II & 7 & Mitochondrial ribosomal protein SII \\
\hline U16163 & 2.9 & 2.9 & 2.8 & P4ha2 & $\mathrm{II}$ & Prolyl 4-hydroxylase alpha(II)-subunit \\
\hline D00622 & 2.5 & 2.0 & 3.0 & Lrpap I & 5 & Low density lipoprotein receptor related protein, associated protein I \\
\hline X60676 & 2.3 & 2.4 & 2.2 & Serpinh I & 7 & HSP47 \\
\hline AWI 24432 & 2.1 & 1.8 & 2.5 & Mrpl/2 & II & Mitochondrial ribosomal protein LI2 \\
\hline Al839392 & 2.0 & 2.0 & 2.1 & Aars & 8 & Alanyl-tRNA syntase \\
\hline \multicolumn{7}{|c|}{ Transcription/replication } \\
\hline D49473 & 3.4 & 3.0 & 3.7 & Sox 17 & 1 & SRY-box containing gene 17 \\
\hline U5।335 & 2.5 & 2.5 & 2.6 & Gatab & 18 & GATA-binding protein 6 \\
\hline U79962 & 2.4 & 2.1 & 2.6 & Tarbp2 & 15 & TAR (HIV) RNA binding protein 2 \\
\hline D49473 & 2.1 & 1.9 & 2.3 & Sox 17 & 1 & SRY-box containing gene 17 \\
\hline \multicolumn{7}{|l|}{ Transport } \\
\hline DI4077 & 2.2 & 2.1 & 2.3 & $\mathrm{Clu}$ & 14 & Clusterin \\
\hline \multicolumn{7}{|l|}{ Others } \\
\hline M34603 & 2.6 & 2.3 & 3.0 & $\operatorname{Prg}$ & 10 & Proteoglycan core protein \\
\hline AA793009 & 2.3 & 2.0 & 2.7 & Tex 19 & 11 & Testis expressed gene 19 \\
\hline \multicolumn{7}{|l|}{ Unknown } \\
\hline Al846553 & 3.2 & 3.0 & 3.3 & $\begin{array}{l}\text { III } 1002 \\
0 C / 3 R i k\end{array}$ & 15 & Hypothetical protein \\
\hline Al845664 & 2.1 & 2.0 & 2.2 & Grwd & 7 & Glutamate-rich WD repeat containing I \\
\hline
\end{tabular}

a) H, Parp-I-I-ES cells (210-58 and 226-47); W, wild-type cells (JI). 
We further selected the genes that showed relatively high expression levels (the "Flag value" in GeneSpring ver. 6.1 of the genes should be either "Present" (high level of expression) or "Marginal" (moderate level of expression) in all replicates of the genotype within the 893 genes that showed a difference at $\mathrm{p}<0.05$, see Table 1 (corrected)). Among the 85 genes selected by this analysis, there were 61 genes, obviously including the Parp-1 (Adprt1) gene itself, that were down-regulated and 24 genes up-regulated, as listed in Tables 2 (corrected) and 3 (corrected).

\section{Gene expression profile of the livers and EF cells}

In the livers, $3.3 \%(411 / 12,353)$ of genes showed a significant difference in expression level $(p<0.05)$ between the Parp-1 genotypes. In the livers of Parp-1\% mice, $2.0 \%$ $(253 / 12,353)$ of the genes were down-regulated and $1.3 \%$ $(158 / 12,353)$ of the genes were up-regulated $(p<0.05)$. Similar to Parp-1\% ES cells, a higher percentage of the genes, 62\% (253/411), were down-regulated and the remaining 38\% were up-regulated (Fig. 1C-E in the original article [1], and Table 1 (corrected)). The expression of representative marker genes of the liver, including albumin (Alb1) and phosphoenolpyruvate carboxykinase (Pepck), was similarly high in both Parp-1 genotypes.

The heatmaps were constructed using the gene lists containing the 641 genes that showed a difference at $p<0.01$ in livers (Fig. 2B). Parp-1 deficiency commonly altered gene expression profiles in the livers of two mice analyzed (Fig. 2B, and Table 4 in the original article [1]).

\section{Comparison of the profiles among different cell types}

We compared gene expression profiles between Parp-1\% ES cells and the livers. There were no genes commonly upor down-regulated as summarized in Tables 2 (corrected), 3 (corrected), and 4 in the original article [1], namely in the genes showing relatively high expression levels selected by Flag values, although we observed that 7 genes, including Eif2s2 (eukaryotic translation initiation factor 2 subunit 2 beta), Parp-1, and 1 gene Crygs (crystallin gamma $S$ ), were commonly down- and up-regulated in the ES cells and livers $(p<0.05)$, respectively (Fig. 2C (corrected) \&2D (corrected)).

\section{Corrected methods in the text Data analysis}

Data analysis was performed with the GeneSpring ${ }^{\circledR}$ software ver. 6.1 and ver. 7.3.1 (the latest version). For statistical analyses, the fluorescence intensity (raw signal) was normalized to the 50th percentile reading per chip, and then normalized to the median reading per gene. We performed the non-parametric tests with the cross-gene error model being inactive. In the case of Parp-1\% ES cells, 6 replicates consisting of triplicate microarray results from two Parp-1\% ES cell lines were used. We used the triplicate microarray results from the Parp-1+/+ ES cell line, J1. We excluded genes that showed a standard deviation greater than 2.0 in the normalized data of both genotypes, and we started analysis with 9,640 genes and ESTs for ES cells (Table 1 (corrected)). We constructed gene lists only with the genes that showed statistical differences $(p<0.05)$ and 2 -fold or greater differences in normalized expression levels between Parp-1 genotypes. To construct heatmaps, we used GeneSpring ${ }^{\circledast}$ GX ver. 7.3.1 (the latest version).

We regret that this error occurred in the phase of generating the data set in our paper may have caused any inconvenience. In the process of making these corrections, the microarray data were submitted to the gene expression database CIBEX [2] with the following accession number: CBX22.

\section{References}

I. Ogino H, Nozaki T, Gunji A, Maeda M, Suzuki H, Ohta T, Murakami Y, Nakagama $H$, Sugimura T, Masutani M: Loss of Parp-I affects gene expression profile in a genome-wide manner in ES cells and liver cells. BMC Genomics 2007, 8:4I.

2. Center for Information Biology Gene Expression Database [http://cibex.nig.ac.jp]

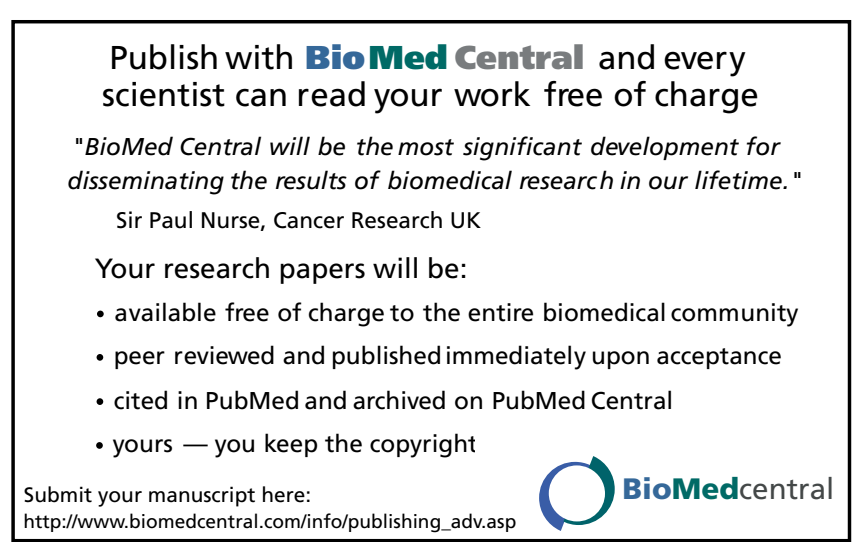

